\title{
REBUILDING OF THE IMPERIAL GARDENS: AN EXAMINATION OF FEUDALISM PRODUCTION WITHIN THE OBJECTIVES OF THE CHINESE MODERNIZATION PROJECT
}

\author{
WEIQI CHU \\ Department of Architecture, DAAP, University of Cincinnati, Ohio, USA.
}

\begin{abstract}
The 'Imperial Gardens,' or the 'Garden of Gardens,' became known as the 'Versailles of the East' when it was built by the Kangxi Emperor in the 1700s. However, unfortunate events such as the Second Opium Wars destroyed much of its magnificent gardens, architecture, and art. Subsequent reconstruction and conservation attempts have generated heated debates between conservationists and those who favour reconstructing the ruins. The Imperial Gardens has been challenged since the 1980s by nationalists who claim it should be modernized because it represents the oppressive feudal system that ruled ancient China. While some view it as a reminder of a painful and oppressive past, conservationists view it as an important treasure that is both historically and architecturally significant. Reconstruction often damages what remains of ruins. It is difficult to recreate the original appearance of a structure as well as use original materials, technology, etc.: it might not be possible to completely rebuild the magnificent and beautiful architecture that once graced the site. Reconstruction could be as damaging as complete destruction, and replacement and alteration employed would be false. In the end there is beauty, life, and truth in age. This paper discusses the importance of architecture that is rich with historical purpose. The Imperial Gardens is a treasure whose ruins should be protected and respected as a critical and legitimate Chinese historical monument. The Imperial Gardens has value, both historically and architecturally, and deserves to be preserved--not restored. Reconstruction would distort its value and status as a monument.
\end{abstract}

Keywords: architectural, debate, historical, heritage, monument, reconstruction, restoration, value.

\section{INTRODUCTION}

China is arguably the oldest surviving civilization in the world. Over time, China has acquired esteemed status worldwide. While she has undergone massive development and growth, her connection with the past is still evident. To visitors the influence of the past is evident in the country's cultural spirit and China in general. The past is visible throughout China in its spoken language, artifacts, and products sold in souvenir shops and kiosks. Advertisement posters display information in a language that has largely remained unchanged for thousands of years, still using long province and city names associated with past dynasties. Yet, despite the richness that is prominent in the culture and language, China appears to be losing its grip on the physical past. Today, the China once endowed with historical reservoirs and memories is slowly losing the significance of its ancient monuments and architecture. Given its rich history, one would expect China to have many classical monuments that relate stories of its past. Its tangible heritage contains architecture, monuments, and historic places which have become neglected and overlooked during modernization. For example, traditional timberwork historically found in Chinese architecture is gradually fading due to problems such as those associated with modern development and an expanding population. This paper explores the importance of the Imperial Gardens to China and highlights why its preservation could ensure the protection and maintenance of its unique historical, cultural, and architectural features. 


\section{HISTORICAL BACKGROUND}

The 'Imperial Gardens,' located next to Tsinghua University and Peking University in the Haidian District northwest of Beijing, is also referred to as the 'Old Summer Palace' (Yuanmingyuan) (Fig. 1). This suburb garden, Yuanmingyuan, is situated twelve kilometres (7.5 miles) from the Forbidden City.

The world-renowned Imperial Gardens could not have achieved unprecedented glory without the contributions and supervision of three great emperors who served during the Qing dynasty: Kangxi emperor (1662-1722), Yongzheng emperor (1723-1735), and Qianlong emperor (1736-1795). The Imperial Gardens was built in 1709 during the Kangxi Emperor's reign and was given as a gift to his fourth son, Prince Yinzhen, the future Yongzheng Emperor. The garden estate was named Yuangming Yuan, or 'Garden of Perfect Brightness' during the Kangxi emperor's reign, and was one of three gardens constituting the site. The others were the Garden of Eternal Spring (Changchun Yuan) and the Elegant Spring Garden (Qichun Yuan). Emperor Yongzheng expanded this complex and added it to his main residence. Improvements included the waterworks (streams, ponds and lakes) that complemented the gently sloping hills and graced the grounds in magnificent fashion. Emperor Qianlong was the first emperor to be interested in European style construction. The Gardens of Eternal Spring (Changchun Yuan) and Elegant Spring (Qichun Yuan) (Fig. 2) were constructed during his reign in 1749 and 1774, respectively.

These two gardens were completed under the supervision of Emperor Qianlong and Yangshi Lei; the latter was a member of a family who designed imperial architecture. The development of Yuanmingyuan peaked during these three emperors' reigns. Western architecture was introduced to the Elegant Spring Garden along with ancient Chinese style architecture characteristic of European style fountains and palaces (Musillo [2]). A set of paintings, the Forty Scenes

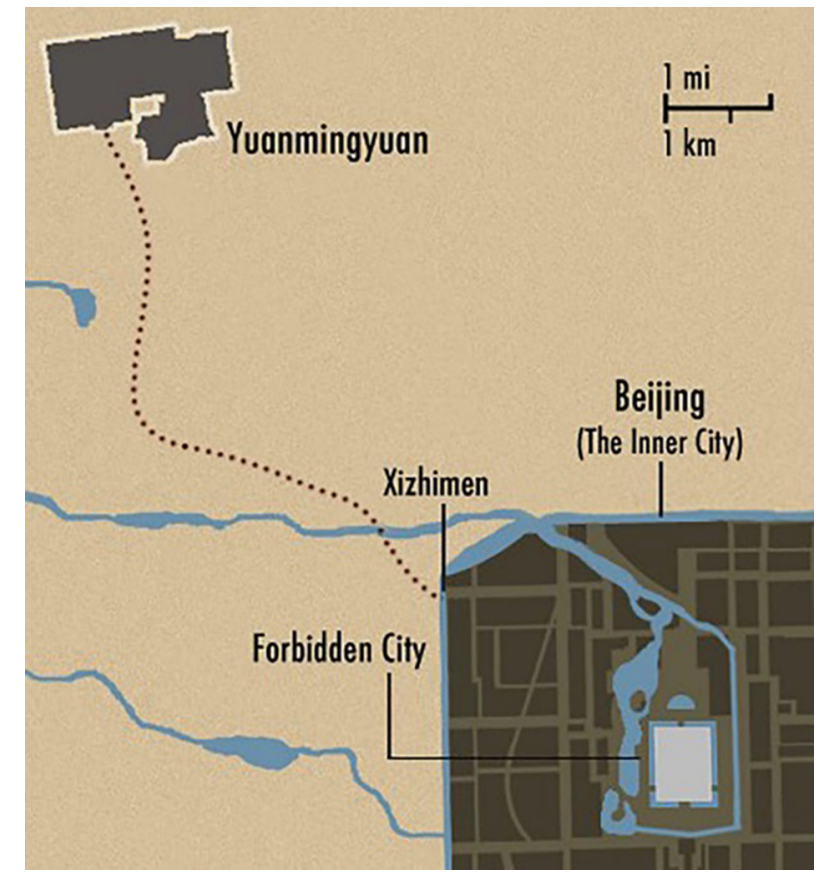

Figure 1: Distance between Yuanmin Yuan and the Forbidden City (M.Li [1]). 


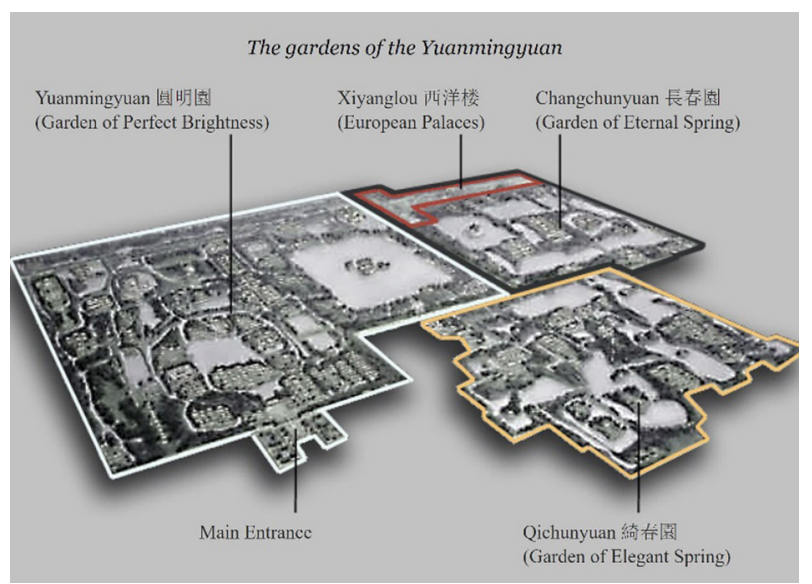

Figure 2: Plan of YuanminYuan (M.Li [1], p. 13).

Views of Yuanmingyuan, was drawn by Dai Tang and Yuan Shen and commissioned by Emperor Qianlong to illustrate European grandiose gardens (M.Li [1] pp. 1-51). Subsequent Qing emperors expanded and perfected the Imperial Gardens until 1860. For example, Emperor Jiaqing, the son of Emperor Qianlong, added pavilions, temples and an ancestral hall. He added the Hall of Diligent Government in the Garden of Elegant Spring (Qichunyuan) which became one of the main residential and working areas. During the Second Opium War that broke out in 1860, the Imperial Gardens were reduced to ashes by looting British and French forces seeking priceless artifacts and porcelain (Endacott [3]). As Victor Hugo wrote the letter to captain Butler on 'The Sack of the Summer Palace', two bandits, France and England, broke into Yuanmingyuan and confiscated jewelry, calligraphies, paintings, sculptures, and other valued items, and burned the Imperial Gardens for three days (Hugo [4]). The Empress Dowager Cixi and Emperor Guangxu unsuccessfully attempted to rebuild the palace at the end of the Qing Dynasty, but empty national coffers made it impossible. The remaining ruins of Yuanmingyuan were further destroyed during the following decades when China was invaded by the Eight-Power Allied Forces, the Anti-Japanese War, the National Liberation war, and the Great Cultural Revolution. The situation did not improve until the Organization of Yuanmingyuan Management was established. Premier Zhou Enlai maintained that the ruins of Yuanmingyuan should be protected because it is a historical witness site and a symbol of national humiliation. Even now, the burning of the Imperial Gardens remains a very sensitive issue in China since it destroyed the benevolence and notable features of the site. The most prominent features today include European style buildings and a few Chinese style buildings in the outer Elegant Spring Garden. Most of the Yuanmingyuan wooden Chinese style buildings were destroyed in the fire except for temples. Most of the structures and fountains exemplifying Western architecture were made of stone and brick and remained for a time after the fire. Paths and water resources were reconstructed as well as a few temples and pavilions such as the Zhengjue Temple finished in 2010 with wooden materials and timberwork. The current maintenance program attempts to avoid further destruction and disintegration.

\section{FEATURES OF THE IMPERIAL GARDEN}

The Imperial Gardens, or 'Garden of Gardens' as it was called in its prime, was known for its magnificent gardens, architecture, and other forms of art and design (Wong [5]). Dominant 
features included multiple halls, gardens, pavilions, lakes, bridges, and temples; galleries in the buildings became archives for multiple and diverse collections of valuable, timeless Chinese architecture and antiques. The Imperial Gardens essentially comprised three major gardens that collectively covered a 3.5 square kilometre area.

The Imperial Gardens virtually demonstrated the concepts of Yin, Yang, and Feng Shui: dominant pillars of Chinese doctrine and culture (Wang [6]). Yin and Yang represent the collusion or understanding of natural and opposing forces, both visible and invisible. The Imperial Gardens through its serene and breath-taking gardens, buildings coexisting with nature, 'cool waters' and air provided a refuge during hot summers--a highly exclusive location for meditation and reflection (Barmé [7]). These features enabled the social elite to connect with the divine and the earthly: a characteristic that has disappeared in many modern world designs. This unification of two grand opposites is enough on its own to promote the gardens' maintenance or partial reconstruction to full glory. It is a clear demonstration of the spiritual in the physical world. Furthermore, the architectural design of the Imperial Gardens encapsulates the principles behind Feng Shui. Evelyn Lip defines feng shui in 'Feng Shui, Environments of Power' as natural forces (wind and water) that exert a particular influence on the exterior/physical environs of working and living areas (Lip and Shui [8]).

The Imperial Gardens design is special in that the garden's construction and location interact with the natural habitat. Recognizing these unique features, restorers feel that reconstruction would greatly deface such uniqueness; it would be nearly impossible to replicate the gardens using modern architectural materials and methods.

The design of the Imperial garden was a combination of ancient Chinese and new European architectural styles. Haiyan Tang was a famous and accomplished European garden landscaper who helped design Yuanmingyuan (number 10-13 in Fig. 3). Baroque style architecture was widely used for Western palaces in Europe during the 18th century. Under the order of Emperor Qianlong, Shining Lang, Zhicheng Wang, and other Western missionaries were responsible for the design of the European Palace in Yuanmingyuan. More than sixty percent of Haiyan Tang's designs and decorations incorporated baroque elements (Yu [9]). Representative Chinese traditional architecture was blended with Western design, especially for the fountain constructed in front of the main building (Fig. 4).

Although naked female sculptures embellish water jets in traditional baroque fountain design, Emperor Qianlong felt that such sculptures were not consistent with ancient Chinese customs. Thus, twelve Chinese bronze zodiacs replaced them as water jets. The sequence of twelve Chinese zodiac animals included a rat, ox, tiger, rabbit, dragon, snake, horse, goat, monkey, rooster, dog and boar. Odd numbered zodiac animals were set on the right side of the fountain and even numbered zodiac animals were placed on the left (Fig. 5). A special timing

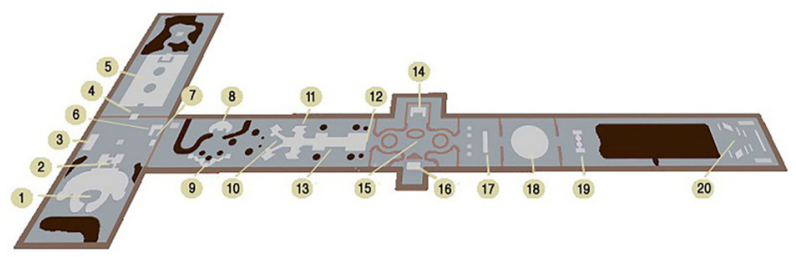

Figure 3: The European palace plan in Yuanmingyuan (Yu, [9]). 


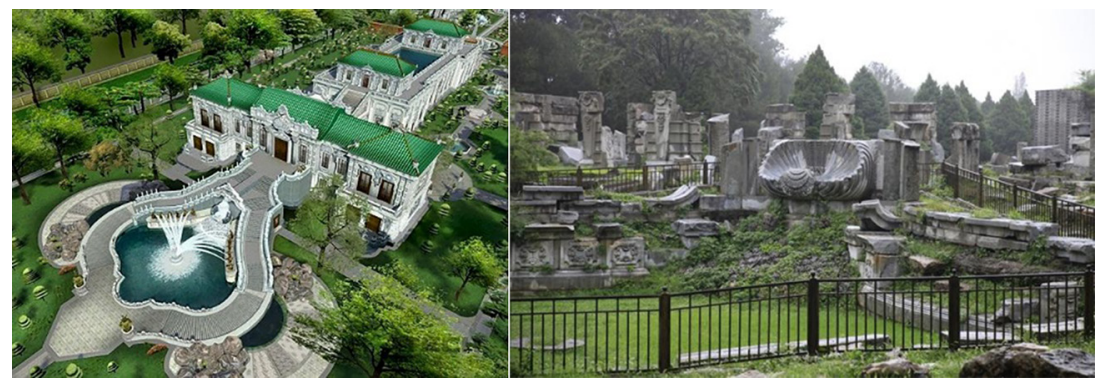

Figure 4: Haiyan Tang (Recovery View) (Image of Haiyan Tang, [10]).

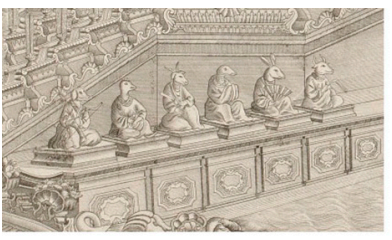

DETAIL: ZODIAC ANIMALS (LEFT)

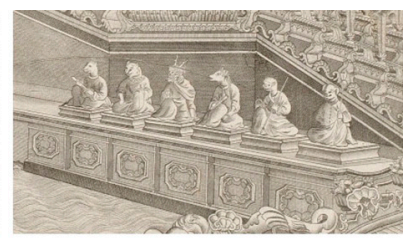

DETAIL: ZODIAC ANIMALS (RIGHT)

Figure 5: The water jets of Bronze twelve Chinese zodiacs in the fountain of Haiyan Tang (The Water Jets in the fountain of Haitan Tang, [11]).

unit called 'Shi Chen' was constructed to control the water feature and was set at two-hour intervals; another setting was set at 12 Shi Chen, a period of the day. During each two-hour interval one of the twelve Chinese zodiac animals sprayed water from its mouth; all twelve Chinese zodiacs sprayed water at meridian hour. This combinational fountain was designed as a water clock fountain. These unique features made the Imperial Gardens prime property that was not only costly, but also highly sought after by the ruling class. Dashuifa (Fig. 6) was another large-scale fountain and featured a special viewing deck on the opposite side of the general viewing area for imperial family members. Another feature was the Huanghua Zhen (Fig. 7) labyrinth for imperial entertainment: imperial members commanded eunuchs or maids to walk the labyrinth as directed.

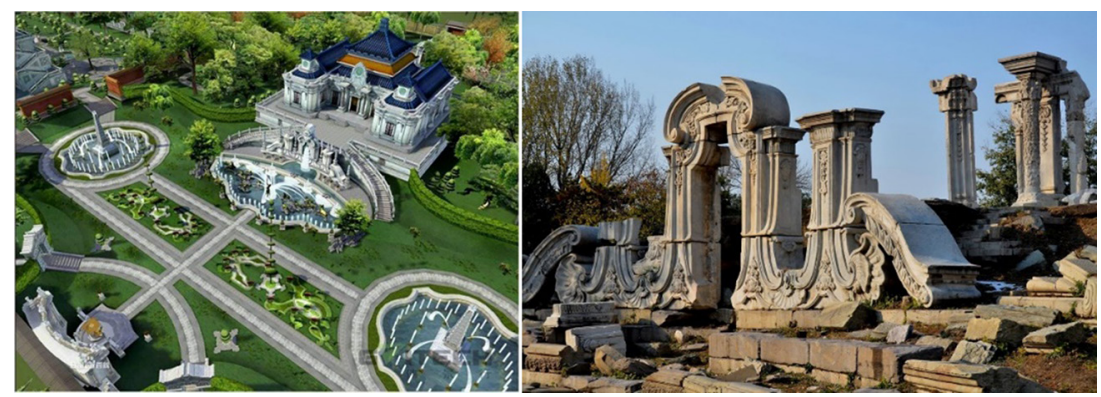

Figure 6: Dashuifa (Recovery View) (Dashuifa, [12]). 


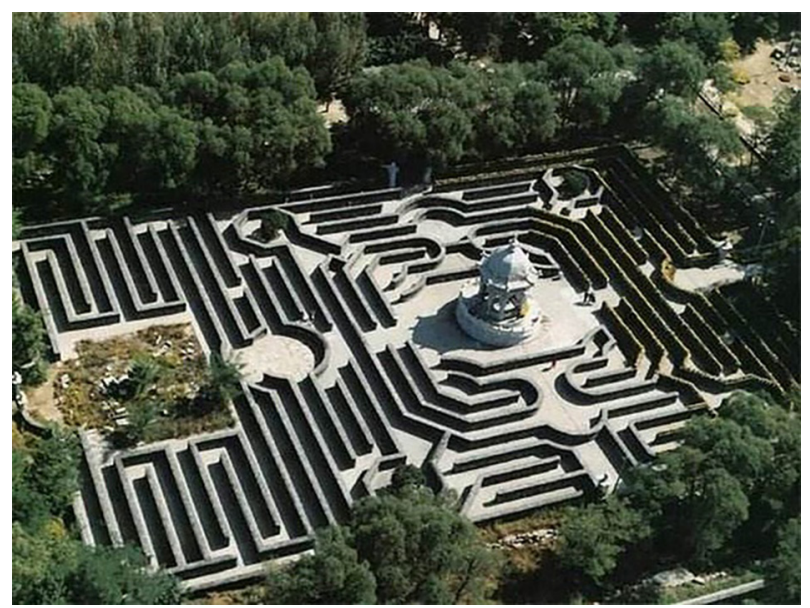

Figure 7: Huanghua Zhen (Recovery View) (Image of Huanghua Zhen, [13]).

\section{DISCUSSION}

Scholars hold diverse views about the future of Yuanmingyuan, all originating from a common understanding of Yuanmingyuan's value and its legacy for future generations. Qing history scholars support the rebuilding alternative because of Yuanmingyuan's architectural vault. Yuanmingyuan represented most ancient Chinese traditional architectures from both sides of the Yangtze River in addition to the popular Western architecture of the 18th century. A rebuilding of Yuanmingyuan would demonstrate the glories of the imperial garden. However, my personal view is that the ruins of Yuanmingyuan are better left in their present state rather than becoming a basic reconstruction of Chinese history. The real value of the current Yuanmingyuan is the status of its ruins. The quondam glory of Yuanmingyuan was lost during the pillage and burning by Anglo-French Allied Forces, and further destruction incurred during subsequent wars. The legacy of Yuanmingyuan is its ruins that carry the message of national humiliation and disaster. The ruins are a historical witness to a grievous history. A replacement program would completely destroy this garden, and a complete reconstruction would only create a new, artificial landscape without real historical or architectural significance. Its historical significance would be destroyed during the process, and newly constructed architecture taking advantage of modern technology and materials would fail to imitate the original work. Furthermore, historical documents that provided a detailed architectural analysis of the original were lost during the long history of warlord dogfights, the Anti-Japanese War, the Liberation War, and the Great Cultural Revolution.

The present case study argues for keeping Yuanmingyuan as a ruin rather than a reconstruction. This research may contribute to future scholarly discussions about the care and historical significance of the Yuanmingyuan ruins. Conservation work will adequately serve the ruins only when its historical significance is fully understood. The importance of the ruins will be lost to future historic development without responsible conservation. Furthermore, popularizing and informing the public about the ruins will contribute to patriotism and assure that Yuanmingyuan will be retained for future generations to appreciate. 


\section{HERITAGE AND THE IMPERIAL GARDENS}

Heritage is referred to as the selective use of different periods of the past, present, or future as objects of social importance (Ahmad [14]). The Imperial Gardens was a direct product of the feudal system under the ownership and management of the imperial family, and now serves as a historical monument. The site fell into ruins after the downfall of the feudal system, and while it appears worthless, it relates valuable information about the past, albeit a painful one (Lee [15]). Since all monuments deserve status as an object of particular historical value, the Imperial Gardens qualifies to be considered, treated, and regarded as an object of heritage.

Apart from its significance to global cultural diversity, the Imperial Gardens has been regarded as one of the most important architectural structures in Chinese architectural history. Its development employed the most advanced and refined construction skills of its time such as the complicated bracket system in timberwork structures and the use of huge stone blocks as building materials before the use of cranes. The Imperial Gardens is exemplary for architects in every period of study, thanks to the skills of its builders (The Imperial Gardens [16]).

The Imperial Gardens is important to the study of architecture in addition to being a cultural inheritance of great significance (Tsui [17]). It has enjoyed the title of 'Museum of Architectures' since its construction because it covered a 3.5 square kilometer area containing most garden designs found from North to South China combined with creative Western landscape gardens, and it contained replicas of all famous buildings in ancient China and modern Western countries. Furthermore, the Imperial Gardens is considered an aggregate of garden arts (Kleutghen [18]).

\section{CHINA'S PERSPECTIVES TOWARDS CONSERVATION}

Supporters and opponents of reconstruction have debated the value of preserving historical, cultural, and traditional architectural sites in China. While nationalists such as Sicheng Liang, Tingfang Ye, and Zuolai Wu view historical sites as feudal objects that deserve destruction, conservationists such as DaoCheng Wang and Qing historians feel that such an endeavor might distort critical historical truths. The debates relating to the gardens of Yuanmingyuan (Imperial Gardens) have been especially contentious due to the site's relationship with historical 'wounds'. It evokes emotional pain associated with Opium Wars that represent disdain for Chinese heritage and culture. The unique history of the Imperial Gardens has inspired debate that ranges from maintaining the site as a ruin to complete reconstruction of the gardens and buildings. It has been difficult to reconcile various values and meaning associated with the gardens both politically and historically. According to Sicheng Liang, a heritage conservationist, 'not changing the original condition' is the only way to ensure that the rarity, beauty, and ingenuity of Beijing and its early architecture are kept intact (Lai et al. [19]). Liang proposes that an aged building should not be rebuilt to have a bright and new appearance since there is value in age. Maintaining architecture in its present condition has now been adopted into law in China. The 1982, 'Law of the People's Republic of China Protection of Cultural Relics' upheld that architecture should not be changed; it should be retained in its original condition in accordance with Liang's views (Du Cros, et al. [20]).

While the Imperial Gardens is associated with past wounds inflicted on China's people and their heritage, it is still meaningful to its people. Sara McDowell, a human geographer at Ulster University, states in 'Heritage, Memory and Identity' that the 'marking' of a place is a universal practice used to represent memory and guarantees that the heritage of a people is 
preserved (McDowell [21]). Such heritage sites enable people to connect with past events and memories as they inherently develop a sense of ownership, identity, and meaning. Tim Creswell, also a human geographer, notes that heritage sites are thus locations where people connect physically and/or emotionally in a way that is inspired by feelings of ownership and identity (Creswell [22]). The Imperial Gardens is a critical part of China's heritage due to its Chinese identity, values, and design, and its preservation would ensure that China remembers her past by selectively using the past as a resource for both the present and the future. Maintaining the truths of the ancient site promises to have great research potential: it enables an appreciation of the past and transmits information about the past to the future.

Some claim that architectural ruins need to be reconstructed to the level of their original glory to be culturally meaningful (Dreyer [23]). Such a stance is represented by Daocheng Wang who is against maintaining the Imperial Gardens in its original state. Alois Riegl delineates various types of competing values to consider when making decisions to preserve or conserve historical sites in 'The Modern Cult of the Monument: Its Character and Its Origin'. According to their classification, monuments can be intentional (commemorative), unintentional (historic), or age-valued (dated). Hence, the Imperial Gardens is both an unintentional and an age-valued monument since its construction is both historically artistic and aged. The views of Riegl contrast with those of McDowell, given the historical claim that relative art value is opposed to age-value.

According to Riegl, architecture should only be preserved if it is restored to its original form, whether it is closer to or unconditionally complete (Riegl [24]). If Riegl's opinions can be applied to Imperial Gardens preservation, they would support the redevelopment of the site: its gardens and architecture should be rebuilt to their original form. However, while this type of classification promotes the 'whole' for the creation of culturally meaningful work, such opinions lead to distortion and loss of heritage value. By restoring the Imperial Gardens ruins to their original state, Chinese society would lose its connection to the Imperial Gardens' unique designs, art, and originality, since new materials would not equate with the materials used originally. Furthermore, current tools, devices, and artists would not be able to accurately replicate features of the ancient architecture since much of the construction information has been lost. Such action would contribute to the loss of even more unique features of ancient art to which the Chinese can identify, relate and own.

The Chinese government felt they must rebuild the Imperial Gardens. The public viewed the remains of the Imperial Gardens as a symbol of humiliation, for it witnessed wars and suffered from invaders and mobsters. However, the majority of experts such as Tingfang Ye and Sicheng Liang held that the Imperial Gardens should remain in their present condition because, even if the most advanced technology to rebuild it were employed, the Imperial Gardens would not approximate its original grandeur (Wong [5]). Worse, rebuilding would cause damage to what remains of the site. Research experts such as Daocheng Wang lobbied the Chinese government to rebuild the Imperial Gardens to remind the Chinese people of the garden's brilliance and contribution to global architectural diversity.

Yuanmingyuan is often mentioned in association with the ruins of Dashuifa which is the first image in most peoples' minds when they hear 'Yuanmingyuan' (Fig. 6, Right). The reconstruction of Dashuifa to its former glory is likely symbolic of rebuilding and restoring the former glorious Yuanmingyuan in most people's thinking. Yang Liu works in the Yuanmingyuan Management Department Office and is a building expert doing research on Yuanmingyuan and Beijing Historical Culture. Most of his research focuses on the history of Yuanmingyuan such as the Quondam Summer Palace-Yuanmingyuan, Who Collects 
Yuanmingyuan. He mentions that the European Palace and the ruins of Dashuifa covered only $2 \%$ of the Yuanmingyuan area; the other $98 \%$ of the area contained Chinese traditional architecture. The reconstruction project plays an important role in popularizing and educating the traditional culture of Yuanmingyuan. Wang Daocheng is a professor of the Qing Dynasty Research Institute at Renmin University of China, and wrote several works about Yuanmingyuan to further people's understanding of this architectural treasure. Yuanmingyuan and The Architecture Style and Features of Yuanmingyuan is the crystallization of Chinese wisdom. Wang once stated in an interview that he favors reconstruction to protect traditional culture because not all architectural features were destroyed during the burning and further destruction of the site during the Republican Era and Cultural Revolution, and that we can learn from the surviving buildings, especially the methods of construction. Furthermore, if citizens had realized the significance and magnificence of Yuanmingyuan before 1980, they may not have cultivated the site for farming and poultry breeding. At that time there was a tremendous influx of citizens moving into the Yuanmingyuan during the Great Leap Forward period and during the Great Cultural Revolution, reaching a population of 2,000.

Many damaged installations and buildings worldwide such as the Greek Parthenon and the Roman Coliseum were not rebuilt following destructive wars. Kaiser Wilhelm Memorial Church, a famous building located on Kudamm Street in Berlin, Germany, was severely damaged during the Second World War. Although many modern towers and commercial buildings have been constructed around the church, the Berlin government and citizens never attempted to rebuild the church to commemorate Kaiser Wilhelm. The unified attitude of the German people was that the church ruins would be a reminder of the consequences of war (Gerlach [25]). Weixi Cong wrote in 'Perfect and Mutilation' that both perfection and mutilation are the opposite of beauty because of distinct aesthetic standards and views. The Yuanmingyuan ruins bring to mind Chinese history, even historical fragments that elicit shame. Cong's view is that the Yuanmingyuan should be retained as a ruin (Cong [26]). Zuolai Wu, a focus scholar for the study and research of Chinese culture, was asked in an interview why the Chinese were so addicted to the idea of rebuilding the Yuanmingyuan ruins when the Greeks did not plan to reconstruct the ancient Olympic arena. Even if the Yuanmingyuan were reconstructed, it would just be a new garden and replica without real historical significance. Tingfang Ye, a renowned Chinese scholar and professor at Peking University, participates in many seminars and leads social issue discussions. In regard to rebuilding the Yuanmingyuan, he stated, 'Ruin is a sense of beauty,' and to keep the current condition of the Yuanmingyuan is to conserve the 'scene of crime'. A replacement could not represent real Chinese history and would be a vainly concealed attempt to erase fact and history.

To rebuild Yuanmingyuan or to retain it as a ruin is a debate that has continued since 1950 . The ruins would have been drastically destroyed without the intervention of Zhou Enlai, the prime minister of new China. He persuaded Sicheng Liang to save it as a relic and to avoid using it for other purposes. On one hand, a restoration would popularize traditional Chinese architecture, culture, and the historical significance of the Yuanmingyuan, and on the other hand, preserving the ruins would remind people of their national humiliation and tragic history.

A replica of Yuanmingyuan was built in Hengdian, Zhejiang Province using a 1:1 size ratio and covers more than 1,153 acres. Ninety-five percent of the buildings in the Imperial Gardens have been constructed using new materials and technology to recover original shapes of the ancient buildings, at an estimated cost of 30 billion yuan. The buildings replicate the original structures, capturing the textures of original materials, colors, shapes and decorations. For example, the bucket arch (a system of brackets inserted between the top of a column and a 
crossbeam) has been retained. In the original palace, the bucket arch was hand carved in wood by craftsman; however, modelling and concrete replaced this traditional craft in the new construction. The newly replicated palace will not only allow visitors to see the glory of Chinese history and culture, but also demonstrate traditional Chinese crafts. However, Sicheng Liang suggests that the new Yuanmingyuan does not have historical and architectural significance because it was built using modern technology and materials. It was a vanity project that exhausted builders and drained treasury funds. China is still in a developmental stage, and using enormous amounts of money for a Yuanmingyuan reconstruction is inappropriate at this time. For instances, the Zhengjue Temple in Yuanmingyuan has undergone reconstruction since 2002. The government and relevant departments spent nine years and 36 million RMB rebuilding it--an expensive and laborious program.

A degree of maintenance in the future will be necessary and essential to avoid further deterioration of the ruins. The existing ruins of Yuanmingyuan are primarily made of stone and need to be protected from additional weathering and deterioration. A combination of physical and chemical methods can be utilized for this purpose such as sun shelters and coatings of organic silicon to reduce oxidation.

Rapid technological developments may make it unnecessary to completely reconstruct the Yuanmingyuan. Material additive manufacturing (3-dimension printing) may make it possible to reproduce cost effective models of the original old Summer Palace to show the architectural styles used in its construction, as well as to print reproductions of damaged and intricate architectural replacement parts. Additionally, 3D printers could be used to print frames and structures such as bucket arches, crossbeams and gables to help visitors understand interesting Chinese traditional architectural structures, and to show the contrast between traditional Chinese and modern technological cultures. Such a method could reflect the historical value of this ancient building at a reasonable cost. After all, a reconstruction only recovers the original appearance of a building which has no historical significance.

\section{CONCLUSION}

In conclusion, many factors need to be addressed when conservation and maintenance decisions of the Imperial Gardens are made. The Imperial Gardens is arguably the most important of Chinese ruins: it is a link to China's past and deserving of elevated status and recognition (Ryckmans [27]). Historically, the Imperial Gardens has been home to ruling dynasties that have shaped China's culture, values and customs. However, the Imperial Gardens has been equally a source of pain and hatred for ordinary citizens who feel it was a tool of oppression used by the elite to gain prestige. Nevertheless, the site is critical to the nation's history as it demonstrates the resilience, ingenuity, and determination of the Chinese people. Even after being destroyed by the English and the French during wars, the Imperial Gardens has persisted despite being deprived of its unique artifacts, architecture, designs and benevolence. Today, its ruins are the practical demonstration of China's past and the memories that the people of China can relate to, and identify with as a source of pride. It is critical to reiterate that the Imperial Gardens deserves to be preserved, as it is an important source of historical, cultural, and architectural information for China. It would be lost in a complete reconstruction.

\section{ACKNOWLEDGEMENTS}

A number of individuals have offered me valuable help in writing this paper, including my advisor, editors, and my family. Their comments and help have assisted me in better realizing my shortcomings, so I can improve in the future. 
First, I would like to extend sincere gratitude to my advisor, Professor Edson Cabalfin, who with extraordinary patience, profound knowledge, and continuous encouragement helped me locate the necessary literature and materials needed for the project and offered me writing inspiration. Although busy, he provided me with detailed feedback and unique insight as the paper's first reader. Without his enlightened instruction and impressive help, I could not have successfully completed it.

Second, I would also like to offer sincere thanks to my editors, Fred Vallier and Jane Vallier. In addition to being responsible for correcting grammar, sentence structure, and English expression, both of them provided thoughtful opinions and reference suggestions. Without their serious, rigorous, and responsible attitudes, the paper could not have been smoothly written.

Finally, I would like to express my deepest gratitude to others who helped me directly and indirectly, and to the authors of printed materials used to complete this paper.

\section{REFERENCES}

[1] M.Li, L., "The 40 Scenes." The Garden of Perfect Brightness-1: The Yuanmingyuan as imperial paradis (1799-1860), MIT Visualizing Culture, p. 13, 2012.

[2] Musillo, M., Mid-Qing Arts and Jesuit Visions: Encounters and Exchanges in Eighteenth-Century Beijing. In ed. Susan Delson, Ai Weiwei: Circle of Animals. Prestel Publishing. pp. 146-161, 2011.

[3] Endacott, G.B., A Biographical Sketch-Book of Early Hong Kong, Hong Kong University Press, pp. 45, 2005.

[4] Hugo, V.M., The Chinese Expedition: Victor Hugo on the Sack of the Summer Palace. November 1861. Online Resource: https://www.napoleon.org/en/historyof-the-two-empires/articles/the-chinese-expedition-victor-hugo-on-the-sack-of-thesummer-palace/

[5] Wong, Y.T., A Paradise Lost: The Imperial Garden Yuanmingyuan, University of Hawaii Press: Honolulu, 2001.

[6] Wang, Y., A Comprehension of Feng-Shui and Its Relevance to Landscape Architecture, Swedish University of Agricultural Sciences, p. 15, 2012.

[7] Barmé, G., The garden of perfect brightness, a life in ruins. The George Ernest Morrison Lecture in Ethnology (57th: 1996: Australian National University, Canberra). East Asian History, 11, p. 111, 1996.

[8] Lip, E. \& Shui, F., Environments of Power, A Study of Chinese Architecture, Academy: London, 1995.

[9] Yu, J., Lecture: Architectural Decoration and Baroque Style in European Garden in Yuanmingyuan, 2013.

[10] Image of Haitan Tang, Online Source: http://www.360doc.com/content/15/1104/ 17/16737474_510730313.shtml https://baijiahao.baidu.com/s?id=1619429955495397 $970 \& w f r=$ spider $\&$ for $=$ pc

[11] Image of the Water Jet in the Fountain of Haiyan Tang, Online Source: http://blog.sina. com.cn/s/blog_cce1a6720102vj30.html

[12] Image of Dashuifa. Online Source: http://blog.sina.com.cn/s/blog_7e6b066f0101a0vx. html http://bbs.zol.com.cn/dcbbs/d657_162531.html

[13] Huanghua Zhen., OnlineSource: http://blog.sina.com.cn/s/blog_5ec48e940100ke3e.html

[14] Ahmad, Y., The scope and definitions of heritage: From tangible to intangible. International journal of heritage studies, 12(3), pp. 298, 2006. https://doi. org/10.1080/13527250600604639 
[15] Lee, H., The ruins of Yuanmingyuan: Or, how to enjoy a national wound. In Places of Memory in Modern China, 7, p. 195, 2011.https://doi.org/10.1163/9789004220966_008

[16] The Imperial Gardens, http://www.yuanmingyuanpark.cn/ (accessed 22 October, 2015).

[17] Tsui, B., Decolonization and revolution: Debating gandhism in republican China. Modern China 41.1 (2015): 59. Publisher Provided Full Text Searching File, (accessed 7 December 2015).

[18] Kleutghen, K., Imperial Illusions: Crossing Pictorial Boundaries in the Qing Palaces, University of Washington Press: Seattle, 2015.

[19] Lai, G., Demas, M. \& Agnew, N., Valuing the past in China: The seminal influence of liang sicheng on heritage conservation. Orientations, 35(2), pp. 88, 2004.

[20] Du Cros, H., Bauer, T., Lo, C. \& Rui, S., Cultural heritage assets in china as sustainable tourism products: Case studies of the Hutongs and the Huanghua section of the great wall. Journal of Sustainable Tourism, 13(2), pp. 179, 2005. https://doi. org/10.1080/09669580508668484

[21] McDowell, S., The ashgate research companion to heritage and identity. Heritage, Memory and Identity, pp. 45, 2008.

[22] Creswell, T., Place: A Short Introduction, Oxford: Blackwell, 2004.

[23] Dreyer, J.T., China's Political System: Modernization and Tradition, 8th edn., Person, p. 23, 2012.

[24] Riegl, A., The modern cult of monuments: Its essence and its development. Historical and Philosophical Issues in the Conservation of Cultural Heritage, 69, p. 83, 1996.

[25] Gerlach, E., Berlin, Kaiser Wilhelm Memorial Church, ed. K. Vanovitych, 5th edn., Regensburg: Schnell und Steiner, 2007.

[26] Cong, W.X., Perfect and mutilation. In the Journal of New Reading Writing, 6, pp. 48-49, 2004.

[27] Ryckmans, P., The Chinese attitude towards the past. China Heritage Quarterly, no. 14, p. 1, China Heritage Project, The Australian National University, 2008. 